\title{
Response to Long Term Exercise Training in COPD
}

\author{
Renukadevi Mahadevan¹, Chaya Sindaghatta², Vijay Samuel Raj Victor³ \\ 1,3 Department of Physiotherapy, JSS College of Physiotherapy, Mysuru, Karnataka, India. \\ ${ }^{2}$ Department of Pulmonology, JSS Medical College, Mysuru, Karnataka, India.
}

The patient is a 64-year-old male. He presented with difficulty in breathing and was diagnosed with COPD (chronic obstructive pulmonary disease) ten years back. He is a farmer and an active smoker, of 18 packs / year for 35 years. He began to experience dyspnoea when performing moderate exertion, dyspnoea grading of 3 as denoted by modified medical research council mMRC (Modified Medical Research Council) and productive cough with sputum, usually in the morning. He is on long-term oxygen therapy of 4 litres of oxygen for 16 hours per day for 2 years. He has a history of hospitalisation six times and 5 - 6 emergency consultations for acute exacerbation in the last 3 years.

The patient was on regular treatment with long-acting inhaled beta- 2 agonist (LABA) inhaler and long-acting anticholinergics or long-acting muscarinic receptor antagonists (LAMA) and corticosteroid (ICS) inhalers 200-400 micrograms ( $\mu$ g) three times a day and mometasone $400 \mu \mathrm{g}$, continuously. The patient's body mass index (BMI) was $20.3 \mathrm{Kg} / \mathrm{m} 2$. His blood pressure was 140 / $80 \mathrm{mmHg}$, heart rate (HR) 74 bpm, respiratory rate (RR) $22 \mathrm{rpm}$ and peripheral oxygen saturation (Sp02) at rest was $95 \%$. Pulmonary auscultation revealed a diffusely reduced breath sounds, and no alterations were found in cardiac auscultation.

The patient's post-bronchodilator pulmonary function test was $52.2 \%$ of forced expiratory volume in 1 second (FEV1). In the six-minute walk test ( $6 \mathrm{mwt}$ ), the patient walked a total distance of 294.4 meters, with variations in heart rate from $74 \mathrm{bpm}$ to $128 \mathrm{bpm}$. Whenever peripheral oxygen saturation was reduced to $88 \%$, the patient had taken rest. The patient took rest two times, at the end of the second minute thirtyfive seconds and the end of the fourth minute forty-five seconds. The body-mass index, airflow obstruction, dyspnoea and exercise (BODE) mortality index were used to measure 4 years survival interpretation. ${ }^{1}$ Saint George's Respiratory Questionnaire chronic obstructive pulmonary disease (COPD) version (SGRQ-C) was used to measure the quality of life (QoL).

After the initial assessment, the patient was enrolled in the pulmonary rehabilitation program. The first three months were supervised, exercise training constituted weekly educational sessions and meeting with the psychology support group and nutrition advice before beginning the exercise intervention. ${ }^{2}$ The patient visited the institution three days per week for exercise training. The exercise constituted aerobic on the treadmill and intensity, in the beginning, was $80 \%$ of the 6MWT speed, and Borg's scale of perceived exertion was 4 as prescribed by American Thoracic Society (ATS). ${ }^{3}$ The components of the program were warm-up sessions, conditioning, resistance exercise and a cool-down session. The patient was also advised home exercise program, which included resistance training using weighted sandbags for three sessions per week. The resistance added was based on 1 repetition maximum (RM) and 10RM. $80 \%$ of $10 \mathrm{RM}$ was the training intensity for resistance training for a larger group of muscles. ${ }^{4}$ The weight was added gradually and ensured their rated perceived exertion (RPE) was at 4 during exercise. The patient's outcomes were recorded after three months of training. After 12 weeks of supervised outpatient exercise intervention, the patient was advised home exercise program for the next 6 months. ${ }^{5}$
Corresponding Author:

Dr. Renukadevi Mahadevan, Professor,

Department of Physiotherapy,

Mysuru, Karnataka, India.

E-mail: renukaramya01@gmail.com

DOI: $10.14260 / j e m d s / 2021 / 182$

How to Cite This Article:

Mahadevan R, Sindaghatta C, Victor VSR. Response to long term exercise training in COPD. J Evolution Med Dent Sci 2021;10(11):849-851, DOI: 10.14260/jemds/2021/182

Submission 15-11-2020,

Peer Review 21-01-2020,

Acceptance 28-01-2021,

Published 15-03-2021.

Copyright (c) 2021 Renukadevi Mahadevan et al. This is an open access article distributed under Creative Commons Attribution License [Attribution 4.0 International (CC BY 4.0)] 
The telephonic conversation call was made once in a week, up to 6 months. A daily log was given, and the patient was reminded to mark the exercise sessions. They were encouraged to do the exercise, and periodic education on selfmanagement of the disease was taught. In the sixth month of follow-up, the outcome measures were recorded. The exercise training mode prescribed at home was walking three days per week and resistance training three days per week. The intensity for walking set at $80 \%$ of the distance walked during 6MWT and instructed that the modified Borg's scale of RPE did not exceed 4 (something hard) during walking.

Further, after six months, the patient was instructed about the home program and insisted follow up once in 3 months and reminded through telephone. The patient continued medications as prescribed by the physician. The patient came two times for follow up and had acute exacerbation twice. There was no hospital admission. Patient educated from time to time, during his visit to the department. History of acute exacerbation / hospitalisation episodes recorded, and the patient was instructed for follow up after three years.

\section{Results}

The result shows mMRC grading improved significantly from grade 3 to grade 2 after 3 months of supervised training and sustained as grade 2 after six months of home exercise. At the end of the third year, the mMRC grade was 2 . This shows that the intervention significantly impacted mMRC grade, which is lesser than the pre-intervention measurement. SGRQ-C significantly reduced after three months and sustained the same after six months, but increased after three years, yet there is a significant improvement compared to preintervention measurement.
There is a significant improvement in 6MWT after three months and six months but decreased after 3 years, but there is a clinically significant improvement compared to preintervention measures. BMI improved from underweight to normal after six months of training and sustained the same after three years. The BODE (body-mass index, airflow obstruction, dyspnoea and exercise) mortality index showed significant improvement after three months and maintained the same after six months and three years, which denotes his mortality rate of $57 \%$ rate of 4 yrs. survival is increased to 67 $\%$ and sustained the same up to 3 years.

There was no hospitalisation for up to 2 years but had one in the third year, which is still a significant improvement compared to the number of admissions before the intervention. The patient had history of hospitalisation 6 times accounting to 2 times per year for the duration of three years, prior to the enrolment of the exercise intervention. On 3-year follow up after exercise, the hospitalisation decreased to 1 time in 3 years. This shows the exercise intervention may have an impact on the number of hospitalisations. The number of consultations due to exacerbation was also reduced. The adherence to exercise training was good (70 \%) for up to six months but predominantly reduced after six months to $40 \%$ by the end of the third year. Knowledge about the disease assessed using Bristol COPD Knowledge Questionnaire (BCKQ) improved after three months and continued to be the same for up to 6 months. After three years, it reduced comparatively but significantly improved compared to preintervention period. Pulmonary hypertension improved from severe to moderate. The results are illustrated in the Table 1.

\begin{tabular}{|c|c|c|c|c|}
\hline Variables & Pre & 3 Month Follow-Up & 6 Month Follow-Up & 3 Yrs. Follow-Up \\
\hline FEV1 (in percentage) & 52 & \multicolumn{2}{|r|}{58} & 54 \\
\hline mMRC grading $^{*}$ & 3 & 2 & 2 & 2 \\
\hline SGRQ-C points (total) $^{+}$ & 64.2 & 58.7 & 54.4 & 56.6 \\
\hline \multirow{3}{*}{$\begin{array}{l}\text { M Borg's scale of RPE (leg fatigue) } \\
\text { Rest in seconds }\end{array}$} & 294 & 348 & 362 & 346 \\
\hline & 5 & 3 & 3 & 4 \\
\hline & 80 & No rest & No rest & No rest \\
\hline BMI $\left(3 \mathrm{Kg} / \mathrm{m}^{2}\right)$ & 20 & 21.4 & 24.3 & 24.1 \\
\hline Pulmonary artery hypertension & Severe & Severe & Moderate & Moderate \\
\hline BODE Index (unit) ${ }^{* *}$ & 5 & 4 & 4 & 4 \\
\hline Oxygen support (litres / minute) & 4 & 2 & 2 & 2 \\
\hline No of times of hospitalisation & 6 & Nil & Nil & 1 \\
\hline $\begin{array}{l}\text { Number of consultations } \\
\text { for acute exacerbation }\end{array}$ & 4 & Nil & 1 & Twice \\
\hline Attendance $\%$ to exercise & $-\cdots--$ & 84 & 76 & 40 \\
\hline BCKQ (Beck COPD knowledge questionnaire) in percentage & 43.49 & 65.54 & 68.34 & 62.22 \\
\hline \multicolumn{2}{|l|}{ Reason for non-adherence } & \multicolumn{3}{|c|}{$\begin{array}{c}\text { No motivation, change in place, weather condition, breathlessness, less enquiry } \\
\text { and reminder caused less motivation }\end{array}$} \\
\hline \multicolumn{5}{|c|}{ Table 1. Pre, Post 3-Month, Post 6-Month and Post 3-Year Changes in the Variables } \\
\hline \multicolumn{5}{|c|}{$\begin{array}{l}\text { Abbreviations: FEV - Forced Expiratory Volume, mMRC - modified Medical Research Council dyspnoea grading, 6mwt - Six-minute walk test, BMI - Body Mass Index, BODE - Body } \\
\text { mass index, airflow Obstruction, Dyspnoea, and Exercise } \\
{ }^{*} \text { change of }>50 \text { meters in COPD, change of } 1 \text { unit in mMRC scale (less data). } \\
{ }^{+} \text {A change of }-4 \text { or less on the SGRQ is considered clinically significant. } \\
{ }_{++}^{+} 6 \text { mwt with Predicted } 631.76 \text { meters. } \\
{ }^{* *} \text { change of } 1 \text { point for BODE index. }\end{array}$} \\
\hline
\end{tabular}

\section{CONCLUSIONS}

The QoL, BODE index, mMRC, the number of hospitalisations and knowledge about disease management improved after implementing three months of closely supervised exercise training and after six months of unsupervised exercise sessions which sustained up to three years. But the adherence to exercise reduced significantly. This shows that these patients need periodic monitoring to help them to adhere to the exercise program. 
Financial or other competing interests: None.

Disclosure forms provided by the authors are available with the full text of this article at jemds.com.

\section{REFERENCES}

[1] Celli BR, Cote CG, Marin JM, et al. The body-mass index, airflow obstruction, dyspnoea and exercise capacity index in chronic obstructive pulmonary disease. N Engl J Med 2004;350(10):1005-12.
[2] Cote CG, Celli BR. Pulmonary rehabilitation and the BODE index in COPD Eur Respir J 2005;26(4):630-6.

[3] ATS Committee on Proficiency Standards for Clinical Pulmonary Function Laboratories. ATS statement: Guidelines for the six-minute walk test. Am J Respir Crit Care Med 2002;166(1):111-7.

[4] Lacasse Y, Goldstein R, Lasserson T], et al. Pulmonary rehabilitation for chronic obstructive pulmonary disease. Cochrane Database Syst Rev 2006;4:CD003793.

[5] McCarthy B, Casey D, Devane D, et al. Pulmonary rehabilitation for chronic obstructive pulmonary disease. Cochrane Database Syst Rev 2015;2:CD003793. 